\title{
BMJ open Trends in ischaemic heart disease hospitalisation and case fatality in the Hong Kong Chinese population 2000-2009: a secondary analysis
}

\author{
P H Chau, ${ }^{1} \mathrm{M} \mathrm{Wong}^{2}{ }^{2} \mathrm{Woo}^{2}$
}

To cite: Chau PH, Wong M, Woo J. Trends in ischaemic heart disease hospitalisation and case fatality in the Hong Kong Chinese population 2000-2009: a secondary analysis. BMJ Open 2013;3:e002963. doi:10.1136/bmjopen-2013002963

- Prepublication history for this paper is available online. To view these files please visit the journal online (http://dx.doi.org/10.1136/ bmjopen-2013-002963).

Received 28 March 2013 Accepted 11 July 2013

${ }^{1}$ School of Nursing, The University of Hong Kong, Pokfulam, Hong Kong, Hong Kong

${ }^{2}$ Department of Medicine and Therapeutics, The Chinese University of Hong Kong, Shatin, Hong Kong, Hong Kong

Correspondence to Dr Chau P H; phchau@graduate.hku.hk

\section{ABSTRACT}

Objectives: This study examines the recent trends in ischaemic heart disease (IHD) incidence and case fatality in Hong Kong and explores the possible risk factors.

Design: Retrospective observational study. Setting: All public hospitals in Hong Kong.

Outcome measures: Incidence rate was defined as the number of IHD inpatient episodes divided by the size of the corresponding population. Short-term and long-term case fatality rate was defined as deaths from all causes occurring within 30 and 31-365 days, respectively, divided by the number of IHD inpatient episodes among the corresponding population.

Methods: Poisson and logistic regression models were used to examine the IHD incidence and shortterm/long-term case fatality trends, respectively, for different age and sex groups.

Results: IHD incidence was stable in most age groups. However, the incidence in men aged 15-24, $35-44$ and $\geq 85$ years showed increasing trends, whereas the incidence in men aged 55-64 years and women aged 35-74 years showed decreasing trends. Overall, the short-term/long-term case fatality rates were unchanged over time for both sexes. Short-term case fatality showed increasing trends in women aged $65-74$ and $\geq 85$ years, while long-term case fatality in men aged 55-64 and 75-84 years and women aged $\geq 75$ years showed increasing trends.

Conclusions: Hong Kong trends resembled those in the USA, England and Wales, showing stable or slow decline in the IHD rates, while increasing trends were observed for some age groups, particularly young adults. Public health promotion efforts should focus on reducing cardiovascular risk factors, such as hypertension prevalence.

\section{INTRODUCTION}

According to the WHO, ischaemic heart disease (IHD) is the leading cause of mortality worldwide, accounting for $12.8 \%$ of deaths. ${ }^{1}$ The Global Burden of Disease Study 2010 reported that IHD was the leading cause of death in 2010. ${ }^{2}$ The American Heart

\section{ARTICLE SUMMARY}

Article focus

- Ischaemic heart disease (IHD) incidence and case fatality rates show diverse trends in different populations, with a slow decline in the USA and an increasing trend among certain age groups in England and Wales.

- As unfavourable trends emerge in risk factors, it is uncertain if IHD trends in the Hong Kong Chinese population will follow those of Caucasian populations.

- This study examines the recent trends in IHD incidence and case fatality rates in the Hong Kong population aged 15 years and above and explores the possible risk factors related to such trends.

\section{Key messages}

- On the basis of the inpatient data, there was no overall decline in IHD incidence. However, the incidence for men aged 15-24, 35-44 and $\geq 85$ years increased, whereas that for men aged 55-64 years and women aged 35-74 years decreased.

- Overall, the short-term and long-term case fatality rates were unchanged over time for both sexes; some age groups (men aged 55-64 and 75-84 years and women aged $\geq 65$ years) showed an increasing trend.

- The increasing prevalence of hypertension may account for this observation, and this highlights the need for directing public health promotion efforts towards measures such as reducing salt intake to reduce hypertension prevalence.

Association noted that if there is a decline in cardiovascular disease (CVD) mortality that exceeds CVD incidence, a stable high burden of disease would occur. ${ }^{3}$

Risk factors for IHD include tobacco smoking, hypertension, diabetes, overweight, sedentary lifestyle and unhealthy diet. When the risk factors are controlled properly, IHD can largely be prevented. In analysing avoidable mortality, it is assumed that half of all 


\section{ARTICLE SUMMARY}

Strengths and limitations of this study

- The use of a territory-wide database that captures approximately $90 \%$ of all inpatients with IHD in Hong Kong, and the availability of reliable survival data enables the investigation of case fatality. Furthermore, the longitudinal data allow for examination of IHD trends over a decade.

- This study is limited by the fact that secondary data analysis does not allow for examination of risk factors at the individual level. Moreover, the trends in the IHD incidence and case fatality rates of patients who did not have an overnight hospital stay, as well as those who died before hospital arrival, in the accident and emergency department, or before inpatient admission, could not be captured.

IHD deaths are avoidable. ${ }^{4}$ When Hong Kong was compared with Western cities (Paris, Inner London and Manhattan), it was found that IHD ranked first for avoidable mortality among the Western cities, but only fourth in Hong Kong. It was speculated that Hong Kong had lower IHD mortality rates because of a lower prevalence of smoking and overweight; the effects of ethnic differences on susceptibility to IHD may also play a role. However, there was evidence that risk factors for IHD are becoming more common in the Hong Kong population, as reflected by daily consumption of fewer than five servings of fruits and vegetables and the adoption of a more sedentary lifestyle with little or no leisure-time exercise. If such unhealthy lifestyles become increasingly common, IHD mortality in Hong Kong may increase in the future.

The incidence of IHD and its associated mortality and case fatality rates differ substantially in different populations. ${ }^{5}$ Even within China, increasing as well as decreasing trends in IHD incidence and associated mortality were observed in different populations. ${ }^{6}$ In Denmark, the first-time hospitalisation and case fatality rates for myocardial infarction declined between 1984 and 2008. ${ }^{7}$ Similarly, in England, the incidence of acute myocardial infarction declined between 2002 and $2010 .^{8}$ Meanwhile, some studies have shown that these declines did not apply to all population subgroups. In England and Wales, IHD mortality among men aged $35-44$ years increased from 1984 to 2004, while the decline among the overall population aged $45-54$ years slowed down. ${ }^{9}$ In a US study, it was shown that the decline in IHD mortality rate also slowed down among young adults aged 35-54 years between 2000 and 2002. ${ }^{10}$ On the basis of the diverse trends reported in the literature, it is difficult to predict the IHD trends in the Chinese population in Hong Kong. If the trends in Hong Kong are to resemble and follow those of the USA, IHD incidence in Hong Kong may increase and subsequently decline with a decelerating rate. Furthermore, different age groups may show different trends, as was revealed in the study from England and Wales. The objectives of this study were to examine the recent trends in IHD incidence and case fatality rates in the Hong Kong population and to explore the possible risk factors related to such trends.

\section{METHODS \\ Data}

Inpatient discharge data from the Hong Kong population aged $\geq 15$ years during 2000-2009 were obtained from the Hong Kong Hospital Authority (HA) database. Data from the Clinical Management System and information on the death status of these inpatients (as of mid-2010) were linked according to patients' Hong Kong identity card numbers. Patients who were discharged after 31 December 2009 were not included in this dataset. Information on age, sex and principal diagnosis, as well as information on dates of admission, discharge, and death, was available from the database. The principal diagnoses were coded according to the International Classification of Diseases, Ninth Revision, Clinical Modification (ICD-9-CM) and verified by experts in HA. IHD incidences were identified by the ICD-9-CM codes 410-414 in the principal diagnosis for hospitalisation. Only inpatients were included in this study, regardless of whether admission occurred via the accident and emergency department or via inpatient/ outpatient services. Patients without overnight stay, regardless of the presence of potential IHD symptoms, were not included. The current data covered nearly all inpatients with IHD in Hong Kong, since $88-94 \%$ of these admissions were made to public hospitals (http:// www.ha.org.hk). Because discharged patients might be readmitted for the same IHD episode, hospital admissions within 30 days from the date of discharge were regarded as the same IHD inpatient episode. Deaths occurring within 30 days (short-term case fatality) and 31-365 days (long-term case fatality) of hospital admission were identified by the date of death available in the database. To allow at least 1 year of follow-up for determining long-term case fatality, only admissions on or before 30 June 2009 were included for analysis of longterm case fatality. Population statistics were obtained from the Hong Kong Census and Statistics Department (http://www.cenststd.gov.hk).

\section{Statistical analysis}

Age-sex-specific IHD incidence rates were defined as the number of IHD inpatient episodes divided by the size of the corresponding population and multiplied by 100000 to give a unit of 'per 100000 population'. Age-sex-specific short-term and long-term case fatality rates were defined as the number of deaths from all causes occurring within 30 days and 31-365 days of hospital admission, respectively, divided by the number of IHD inpatient episodes in the corresponding population and multiplied by $100 \%$ to give percentage as the unit. Age-standardised incidence rates were calculated by a direct method using the 2009 
Hong Kong population as the standard. Age-standardised case fatality rates were calculated by a direct method using the total number of IHD episodes in 2000-2009 as the standard. Eight age groups (15-24, 25-34, 35-44, 45$54,55-64,65-74,75-84$ and $\geq 85$ years) were classified for this study.

Age-sex-specific IHD incidence rates and case fatality rates were plotted against time. Since there were diverging trends in the age-sex-specific rates, their trends were modelled separately. Poisson and logistic regression models were used to examine the trends in IHD incidence and case fatality, respectively, with year of admission as the independent variable. In the Poisson model, age-sex-specific population figures were used as the offset population. Data analysis was performed using SPSS V.20.0 (SPSS Inc, Chicago, Illinois, USA). A significance level of $5 \%$ was adopted.

\section{RESULTS}

In total, 179769 IHD inpatient episodes were identified during 2000-2009 among the Hong Kong population aged $\geq 15$ years, and $61.8 \%$ of these episodes occurred in men. Approximately $9 \%$ of the IHD inpatient episodes resulted in subsequent death within 30 days of hospital admission, and another 9\% resulted in subsequent death during 31-365 days after hospital admission (table 1).

The age-standardised IHD incidence rate (per 100000 population) for men aged $\geq 15$ years remained stable at 460.9 in 2000 and 477.9 in 2009, whereas that for women declined from 290.7 to 251.1 over the same time period (table 2). Figure 1 shows the age-sex-specific IHD incidence rates. Poisson regression analysis showed that the incidence rates of IHD increased significantly by $10.7 \%$ per year (95\% CI $1.4 \%$ to $20.9 \%$ ) among men aged $15-$ 24 years, $2.2 \%$ per year (95\% CI $1.0 \%$ to $3.4 \%$ ) among men aged $35-44$ years and $4.1 \%$ per year (95\% CI $1.4 \%$ to $6.8 \%$ ) among men aged $\geq 85$ years, despite the overall stable trend. For women, the incidence rates decreased significantly by $3.0 \%$ per year (95\% CI $0.5 \%$ to $5.4 \%$ ) among those aged $35-44$ years, $5.2 \%$ per year $(95 \%$ CI $4.0 \%$ to $6.4 \%$ ) among those aged $45-54$ years, $6.7 \%$ per year $(95 \%$ CI $5.1 \%$ to $8.4 \%)$ among those aged $55-$ 64 years and $4.0 \%$ per year (95\% CI $2.6 \%$ to $5.4 \%$ ) among those aged 65-74 years, but remained stable for the youngest and oldest age groups. Table 3 provides a summary of the trends analysis.

The age-standardised short-term case fatality rates remained stable for men and women. In 2009, the age-standardised short-term case fatality rates for men and women aged $\geq 15$ years were $7 \%$ and $10.8 \%$, respectively (table 2). Figure 2 shows the age-specific and sexspecific short-term case fatality rates for IHD. Logistic regression analysis (table 3) showed that the short-term IHD case fatality rate for men aged 55-64 years decreased significantly by $2.7 \%$ per year (95\% CI $0.3 \%$ to $5.1 \%$ ) while remaining stable for other age groups. For women, the rates increased significantly by $2.9 \%$ per year $(95 \%$ CI $0.8 \%$ to $5.0 \%)$ for those aged $65-74$ years and by $3.4 \%$ per year (95\% CI $1.9 \%$ to $4.8 \%$ ) for those aged $\geq 85$ years, in the context of the overall stable trend.

The age-standardised long-term case fatality rate for men aged $\geq 15$ years increased from $7 \%$ in 2000 to $8.6 \%$ in 2009 , whereas that for women increased from $10.1 \%$ in 2000 to $11.5 \%$ in 2009 (table 2). However, when analysed by age and sex, the logistic regression analysis (table 3) showed that significant increases were observed only among a few groups. The long-term case fatality rates increased significantly by $2.7 \%$ per year $(95 \%$ CI $0.1 \%$ to $5.3 \%$ ) among men aged $55-64$ years, $2.7 \%$ per year (95\% CI $1.3 \%$ to $4.1 \%$ ) among men aged $75-$ 84 years, $2.2 \%$ per year (95\% CI $0.8 \%$ to $3.7 \%$ ) among women aged $75-84$ years and $2.4 \%$ per year $(95 \%$ CI $0.8 \%$ to $4.1 \%$ ) among women aged $\geq 85$ years. Figure 3 shows the age-sex-specific long-term IHD case fatality rates.

\section{DISCUSSION}

This study examined IHD incidence and case fatality trends among the Hong Kong population aged $\geq 15$ years, using inpatient data. While the overall trends in incidence rates were stable for men and women, trends for different age groups among men and women differed. Men aged $15-24,35-44$ and $\geq 85$ years had an increasing trend, whereas men aged 55-64 years and women aged 35-74 years had decreasing trends. The trends in short-term and long-term case fatality rates for men and women remained stable overall, although men aged 55-64 years had a decreasing trend in the shortterm case fatality rate. Some age groups even showed an increasing trend in short-term case fatality (women aged 65-74 and $\geq 85$ years) and long-term case fatality (men aged 55-64 and 75-84 years and women aged $\geq 75$ years). It should be noted that owing to the small number of IHD cases among those aged 15-24 years, the estimated $10.7 \%$ increase in annual incidence among men of this age group was imprecise, as reflected by the estimate's wide CI (from $1.4 \%$ to 20.9\%). Furthermore, the absence of subsequent mortality in this age group also prohibited the examination of case fatality trends (except short-term case fatality for men). While the case fatality rates among those aged 2534 years could be estimated, abrupt peaks resulted (figures 2 and 3). For example, one death among four inpatient episodes could result in a case fatality rate of $25 \%$.

Our findings resembled those from the England and Wales IHD mortality study in that unfavourable increasing trends were observed for young adult men. ${ }^{9}$ The stable trends found in our study are similar to the levelling off of IHD mortality rates among younger adults in the USA. ${ }^{10}$ Studies in the UK and the USA have suggested that the increasing IHD mortality rates observed among young adults may have been due to 
Table 1 Characteristics of ischaemic heart disease (IHD) inpatient episodes by sex, 2000-2009, Hong Kong

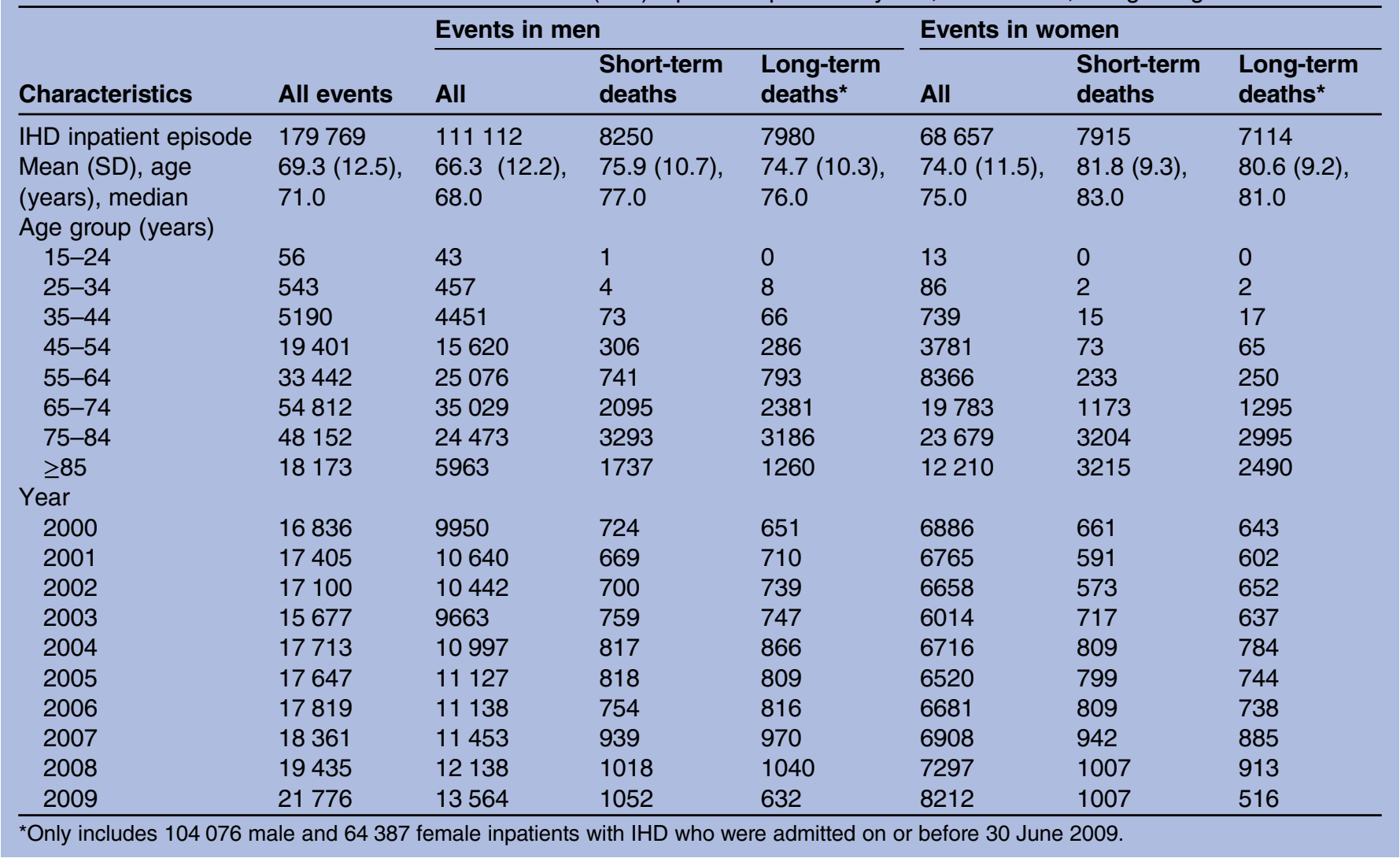

unfavourable trends in risk factors, particularly obesity, diabetes and hypertension. An impact model suggested that improvements in medical treatment contributed to Hong Kong's decline in IHD-related mortality from 1989 to 2001 to a greater extent than risk factor reduction. ${ }^{11}$ However, this explanation may not be applicable to our study in which case fatality included death from all causes. Below, we explore possible explanations for our findings.
The prevalence of daily cigarette smoking in men aged $\geq 15$ years declined steadily from $39.7 \%$ in 1982 to $20.8 \%$ in 2009; meanwhile, that for women declined from $5.6 \%$ in 1982 to $2.6 \%$ in 1990 , but increased again to $4 \%$ in 2005 (http://www.tco.gov.hk/). Studies have shown that the reduction in CVD risk becomes apparent within 5 years of smoking cessation. ${ }^{12}{ }^{13}$ Therefore, if changes in smoking prevalence alone contributed substantially to IHD trends, we would expect a

Table 2 Ischaemic heart disease (IHD) incidence and case fatality rates, 2000 and 2009

\begin{tabular}{|c|c|c|c|c|c|c|c|c|c|c|c|c|}
\hline \multirow{3}{*}{ Age group (years) } & \multicolumn{4}{|c|}{$\begin{array}{l}\text { Incidence rate } \\
\text { (per } 100000 \text { population) }\end{array}$} & \multicolumn{4}{|c|}{$\begin{array}{l}\text { Short-term mortality } \\
\text { rate (\%) }\end{array}$} & \multicolumn{4}{|c|}{ 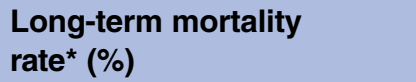 } \\
\hline & \multicolumn{2}{|c|}{ Male } & \multicolumn{2}{|l|}{ Female } & \multicolumn{2}{|c|}{ Male } & \multicolumn{2}{|c|}{ Female } & \multicolumn{2}{|c|}{ Male } & \multicolumn{2}{|c|}{ Female } \\
\hline & 2000 & 2009 & 2000 & 2009 & 2000 & 2009 & 2000 & 2009 & 2000 & 2009 & 2000 & 2009 \\
\hline $15-24$ & 0.9 & 1.8 & 0.2 & 0.7 & 0.0 & 0.0 & 0.0 & 0.0 & 0.0 & 0.0 & 0.0 & 0.0 \\
\hline $25-34$ & 9.5 & 7.7 & 1.8 & 1.8 & 0.0 & 0.0 & 0.0 & 0.0 & 2.1 & 0.0 & 0.0 & 0.0 \\
\hline $35-44$ & 70.8 & 86.7 & 13.3 & 9.6 & 1.7 & 1.8 & 1.1 & 1.6 & 1.1 & 2.1 & 0.0 & 0.0 \\
\hline $45-54$ & 282.3 & 290.6 & 91.5 & 58.5 & 1.9 & 2.1 & 2.7 & 1.8 & 2.1 & 3.0 & 1.2 & 2.2 \\
\hline $55-64$ & 860.9 & 766.5 & 403.9 & 234.7 & 3.8 & 2.6 & 3.0 & 2.5 & 3.5 & 4.3 & 3.5 & 2.2 \\
\hline $65-74$ & 1586.0 & 1562.1 & 1049.7 & 801.1 & 6.3 & 5.9 & 6.0 & 6.0 & 6.2 & 7.6 & 7.0 & 5.7 \\
\hline $75-84$ & 1951.7 & 2331.5 & 1719.1 & 1661.2 & 15.2 & 12.3 & 13.1 & 12.1 & 12.4 & 15.9 & 12.6 & 15.9 \\
\hline$\geq 85$ & 2362.0 & 3005.7 & 2250.6 & 2640.0 & 26.2 & 26.7 & 21.9 & 25.3 & 23.1 & 24.2 & 18.5 & 22.9 \\
\hline$\geq 15$ (age adjusted $\dagger$ ) & 460.9 & 477.9 & 290.7 & 251.1 & 7.9 & 7.0 & 10.7 & 10.8 & 7.0 & 8.6 & 10.1 & 11.5 \\
\hline
\end{tabular}

*Only includes inpatients with IHD who were admitted on or before 30 June 2009.

†The 2009 Hong Kong population and the total number of inpatients with IHD in 2000-2009 were used as the standard populations for calculating age-adjusted incidence rates and case fatality rates, respectively. 
Figure 1 (A and B) Agesex-specific ischaemic heart disease (IHD) incidence rates among the population aged $\geq 15$ years in Hong Kong for 2000-2009.
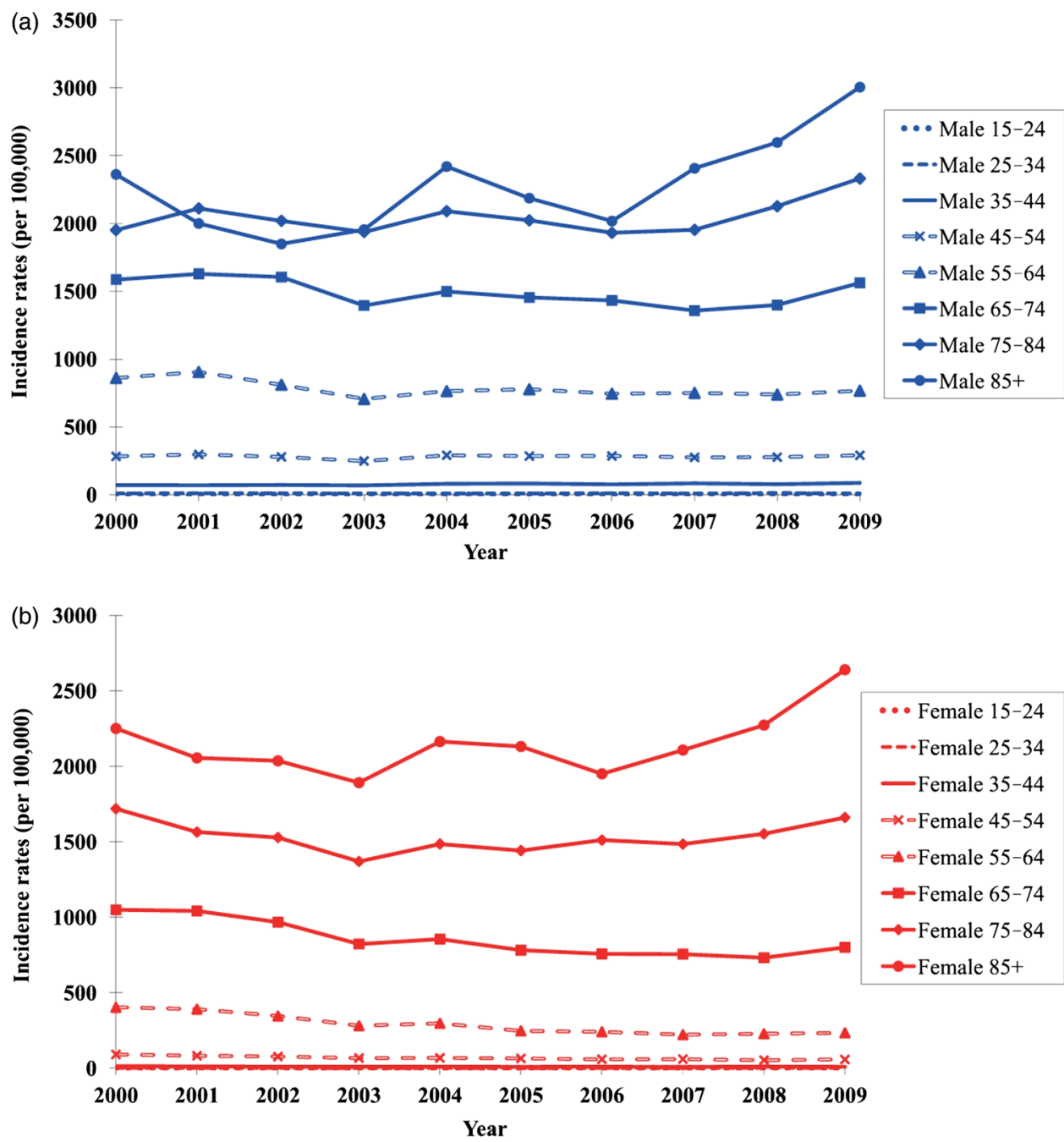

larger reduction in IHD incidence among men than women. However, women aged 35-74 years showed a significant decline in IHD incidence, while men did not. Thus, risk factors other than smoking (which may not have decreasing trends) may have affected the IHD incidence.

Three local health surveys have provided information on the rates of various cardiovascular risk factors, including hypertension, overweight, high cholesterol, diabetes mellitus and physical activity level. ${ }^{14-16}$ Inconsistent trends in different population subgroups were found for these risk factors. Despite age differences in the survey respondents, the prevalence of overweight, high cholesterol and diabetes mellitus appeared to have decreased, with a greater decrease among women than men. The proportion of men and women who did not perform exercise for a month declined slightly, from over to below a half of the respondents. In contrast, the prevalence of hypertension increased markedly for both sexes for all age groups. In 1995-1996, the prevalence of hypertension among men aged 25-34, 35-44, 45-54, 55-65 and 65-74 years was 3\%, 7\%, 17\%, 37\% and 52\%, respectively; in 2003-2004, these rates increased to $11 \%$, $23 \%, 34 \%, 50 \%$ and $66 \%$, respectively. For women, the prevalence of hypertension in 1995-1996 for those aged 25-34, 35-44, 45-54, 55-65 and 65-74 years was $1 \%, 5 \%$, $20 \%, 40 \%$ and $55 \%$, respectively; in 2003-2004, these rates increased to $5 \%, 14 \%, 31 \%, 47 \%$ and $70 \%$, respectively. Those aged $\leq 44$ years had the fastest rate of increase in prevalence of hypertension (ranging from threefold to eightfold). Even among those with the slowest rate of increase (participants aged $\geq 55$ years), the rates also doubled. Moreover, the proportion of men with hypertension increased faster than that of women (except for those aged 25-34 years). Hypertension is a major risk factor of CVD, contributing to $49 \%$ of IHD cases. ${ }^{17}$ Hypertension has also been indicated as a contributing factor to $41 \%$ of CVD-related deaths, compared with $14 \%$ for smoking, $13 \%$ for poor diet, $12 \%$ for insufficient physical activity and $9 \%$ for abnormal glucose levels. ${ }^{3}$ It is possible that the unfavourable trend in prevalence of hypertension outweighed the beneficial effects of the favourable trends in other risk factors, including smoking.

Extreme environmental temperatures may also hasten the onset of IHD, with the elderly population being more vulnerable, ${ }^{18}{ }^{19}$ as observed in the Hong Kong population. ${ }^{20}{ }^{21}$ The trends in IHD incidence and case 


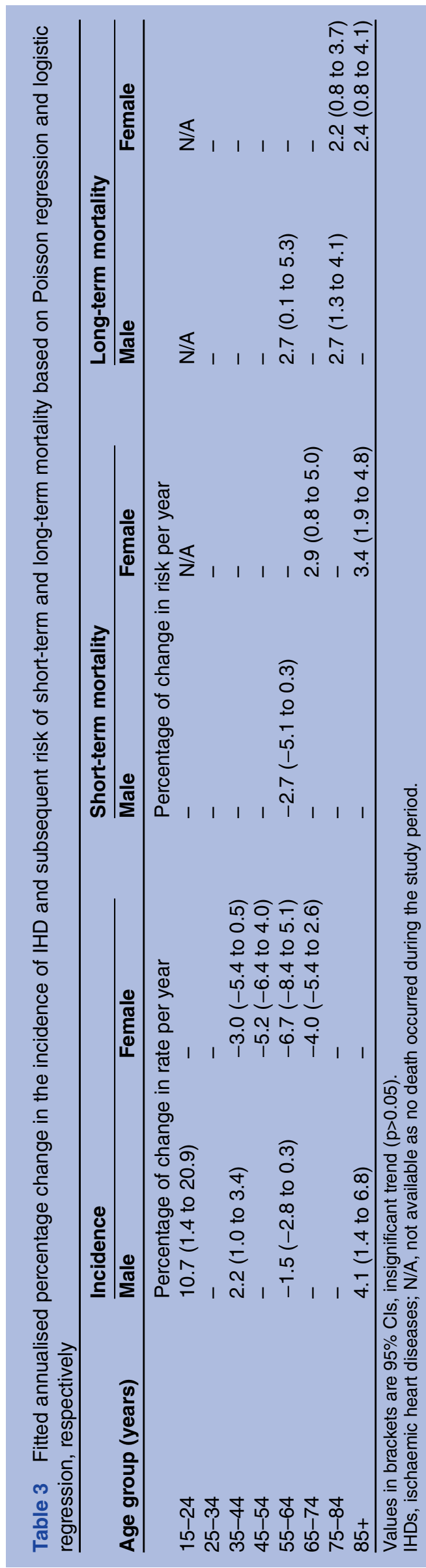

fatality rates observed in our study may partly be explained by trends in temperature extremes. Hong Kong Observatory data (http://www.hko.gov.hk) reveal that the annual number of days with extreme hot or cold temperatures has been generally increasing, although such increase is not statistically significant. This phenomenon may explain the increasing IHD trend among men aged $\geq 85$ years and the non-decreasing trends among all older age groups. However, since younger populations are less likely to be affected by extreme temperatures, temperature is unlikely to have contributed to IHD trends in those groups. Furthermore, air pollution (reflected by reduced visibility) has been associated with increased rates of mortality, respiratory disease and CVD in particular. $^{22}$ The number of 'invisible days' in Hong Kong (http://www. hko.gov.hk) increased sharply from 2000 to 2009, and this may have partly contributed to the unfavourable IHD trends observed.

Another potential IHD risk factor is chronic stress. A recent review found that chronic stress predicted the occurrence of IHD. ${ }^{23}$ Short-term and long-term stresses were related to an increased risk of heart disease and mortality. The workplace is one source of stress for employees. In Hong Kong, men in particular face workrelated and financial-related stress, and their situations are worsened by the concepts of masculinity held in the society, a lack of gender-specific support services for men and men's general reluctance to seek help. ${ }^{24}$ This may explain the increasing incidence of IHD among younger men. Meanwhile, elderly men tend to be more susceptible to socioeconomic and political stressors than women, a concept supported by an association between their mortality rates and environmental stressors. ${ }^{25}$ This may explain the increasing incidence of IHD among men aged $\geq 85$ years. Furthermore, a higher socioeconomic status has been associated with a higher risk of death from IHD, ${ }^{26}$ and growing up in an economically developed environment increased the risk of IHD more among men than women. ${ }^{27}$ These factors may at least partly explain the increasing IHD incidence among younger and older men, but not women. Other reasons for the increasing incidence among those aged $\geq 85$ years may include a poorer in utero environment or more adverse early life experiences aggravated by accelerated growth in a later improved living environment, exposure to periods of economic hardship and poor primary care. ${ }^{28-31}$ However, these reasons apply to both genders, despite a significant increase being found only among men aged $\geq 85$ years.

Survival of out-of-hospital patients with cardiac arrest depends on resuscitation guidelines and practices, as well as response time. ${ }^{32} 33$ In Hong Kong, the outcomes for patients with out-of-hospital cardiac arrest are poor. ${ }^{34}$ Knowledge of cardiopulmonary resuscitation techniques among the public is also poor. ${ }^{35}$ Fewer than $16 \%$ of witnessed cardiac arrests received bystander cardiopulmonary resuscitation and only $11 \%$ of those who received 
Figure 2 (A and B) Agesex-specific short-term ischaemic heart disease (IHD) case fatality rates among the population aged $\geq 15$ years in Hong Kong for 2000-2009.
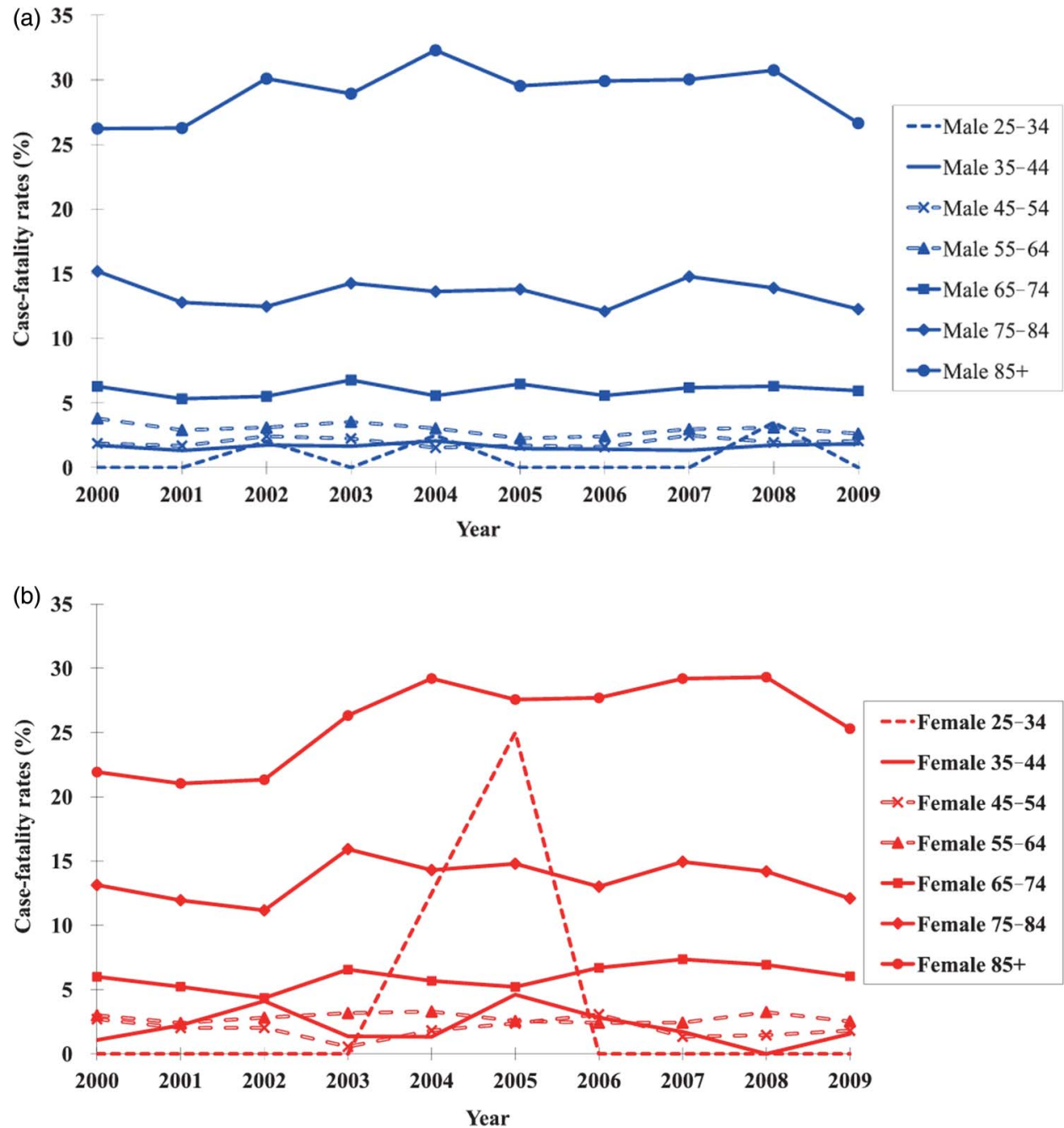

bystander cardiopulmonary resuscitation were discharged alive. ${ }^{36}$ Overall, there is insufficient information relating to out-of-hospital survival for patients with IHD. We are uncertain if the non-decreasing IHD incidence may be related to improvement in out-of-hospital survival for patients with IHD and hence an increasing prevalence of hospital admissions.

This study has certain limitations. Our dataset does not capture $100 \%$ of inpatients with IHD in Hong Kong, since some patients are treated in the private sector. From 2000 to 2009, the proportion of patients with IHD admitted to public hospitals decreased slightly from $93 \%$ to $88 \%$ (http://www.ha.org.hk). However, since the shift from the public to the private system has been slow, the effect should not be strong. We believe that the increase in IHD incidence observed in our study may have been slightly greater if patients utilising the private sector were considered; for those groups that showed decreasing trends, the extent of decline may have been slightly smaller than observed. Using inpatient records for secondary data analysis does not allow examination of trends in underlying risk factors for each individual. Furthermore, the trends in the incidence and case fatality rates of patients who did not have an overnight hospital stay, as well as those who died before hospital arrival, in the accident and emergency department, or before inpatient admission, could not be captured. While the hospitalisation diagnoses were verified by HA experts, no validation study on hospital diagnoses has been published. Since the dataset available did not include the cause of death, deaths subsequent to IHD hospitalisation, for which IHD was the main cause, could not be examined. Nevertheless, we were able to use a territory-wide database spanning a decade to examine IHD trends. We further examined the IHD mortality rates according to the data available from the website of the Department of Health (http://www. healthyhk.gov.hk). It was found (results not shown) that the mortality rates from IHD for most age groups, male as well as female, did not decrease over the past decade, although those for men aged 65-74 years and women aged 55-74 years did decrease. These data were consistent with our findings of unfavourable trends.

Although we could not determine the exact underlying factor(s) contributing to the unfavourable trends in the 

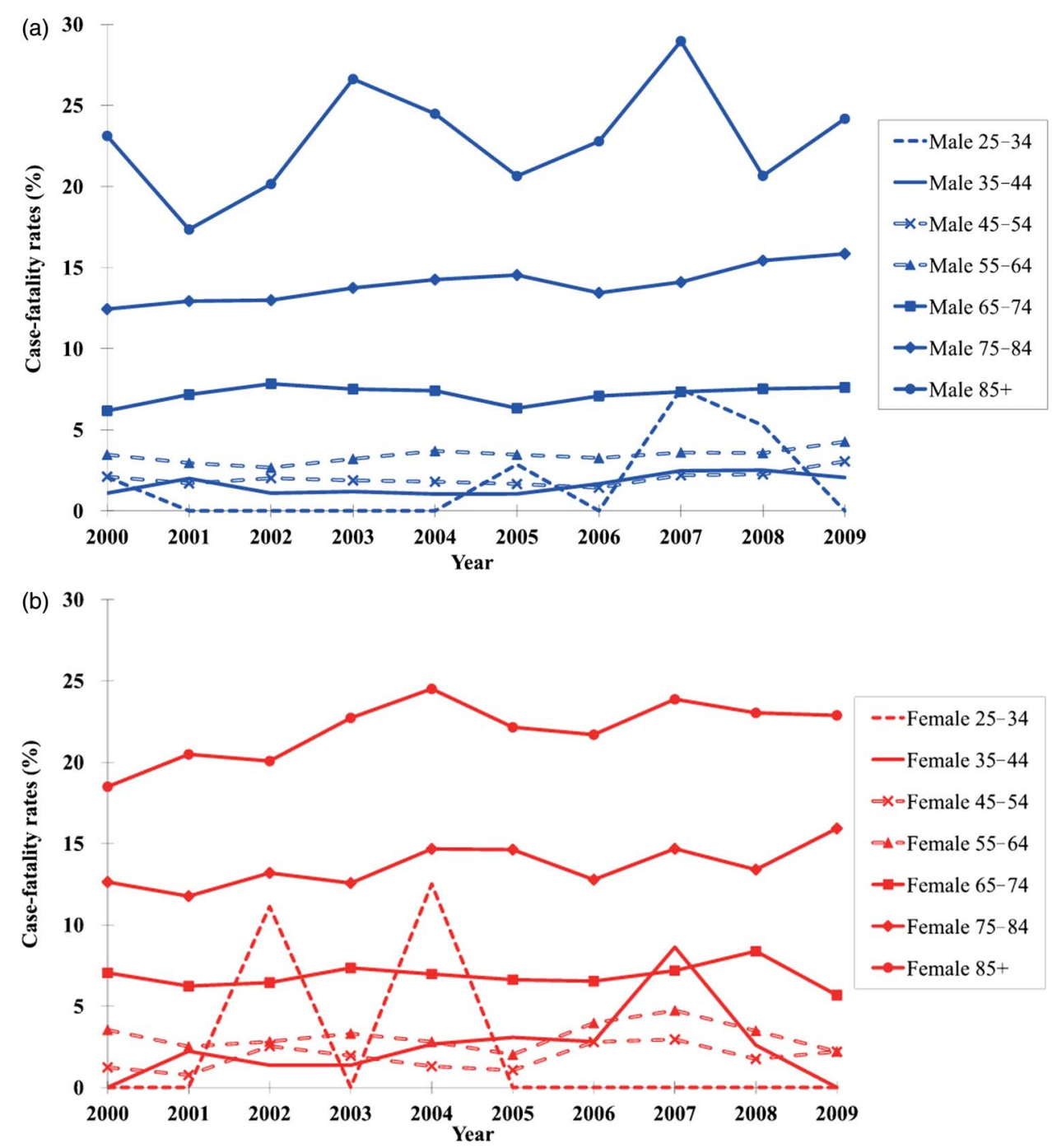

Figure 3 (A and B) Age-sex-specific long-term ischaemic heart disease (IHD) case fatality rates among the population aged $\geq 15$ years in Hong Kong for 2000-2009.

incidence and case fatality of IHD, we were able to identify some of the possible modifiable factors, the most obvious being better population control of blood pressure, even though hypertension does not automatically lead to IHD. Salt intake reduction is known to be an effective nonpharmacological intervention for reducing blood pressure. ${ }^{37} 38$ The diversity and strength of the evidence for the effect of high salt intake on blood pressure is far greater than that for other risk factors, such as low consumption of fruit and vegetables, overweight, excess alcohol intake and low physical activity level. ${ }^{17}$ In a local study in 1998-2000, it was shown that ambulatory blood pressure decreased significantly with salt intake reduction. ${ }^{39}$ However, salt intake reduction has been given less attention in Hong Kong compared with other health promotion programmes (such as smoking cessation). A local population nutrition survey showed that $78 \%$ of adults had a sodium intake over $2300 \mathrm{mg} /$ day, a value considered to be associated with an age-related elevation in blood pressure. ${ }^{40}$ The average salt intake increased from 8 to $9.9 \mathrm{~g} /$ day from $1989-1991$ to
2000-2002, ${ }^{41}$ far exceeding the maximum daily intake of $5 \mathrm{~g} /$ day recommended by the $\mathrm{WHO}^{42}$ Reducing salt intake involves behavioural change that can be difficult to achieve, particularly because such change has to be sustained. Social learning theory and behavioural approaches have been adopted to achieve salt intake reduction. ${ }^{43}$ Lifestyle modification programmes, which have been effective in weight maintenance, ${ }^{44}$ may also provide practical approaches to reducing salt intake.

An increasing IHD incidence, in terms of inpatient admission, combined with a stable case fatality rate will lead to increased healthcare expenditure. The increasing trend in the short-term case fatality rate for women is of concern, and further analysis is required to determine whether this can be explained by gender differences in delayed diagnoses, reduced accessibility to interventional procedures or genuinely poorer outcomes of IHDs for women. Risk factor reduction among IHD survivors remains an important strategy in controlling IHD disease burden. 
Acknowledgements The authors would like to acknowledge the Strategy and Planning Division of the Hospital Authority for the provision of data for this study.

Contributors PHC and JW participated in the conception and design of the study and interpretation of the findings. PHC and MW participated in the literature review and data analysis. All authors contributed to the writing of the article and have read and approved the final version of the manuscript.

Funding This study is part of the project entitled 'CADENZA: a Jockey Club Initiative for Seniors' funded by The Hong Kong Jockey Club Charities Trust. Competing interests None.

Ethics approval Ethics approval was obtained from The University of Hong Kong and The Chinese University of Hong Kong.

Provenance and peer review Not commissioned; externally peer reviewed.

Data sharing statement No additional data are available.

Open Access This is an Open Access article distributed in accordance with the Creative Commons Attribution Non Commercial (CC BY-NC 3.0) license, which permits others to distribute, remix, adapt, build upon this work noncommercially, and license their derivative works on different terms, provided the original work is properly cited and the use is non-commercial. See: http:// creativecommons.org/licenses/by-nc/3.0/

\section{REFERENCES}

1. World Health Organization. The top 10 causes of death. 2011. http://www.who.int/mediacentre/factsheets/fs310/en/ (accessed 11 Jan 2013)

2. Lozano R, Naghavi M, Foreman K, et al. Global and regional mortality from 235 causes of death for 20 age groups in 1990 and 2010: a systematic analysis for the Global Burden of Disease Study 2010. Lancet 2012:380:2095-128.

3. Go AS, Mozaffarian D, Roger VL, et al. Heart Disease and Stroke Statistics-2013 Update: a report from the American Heart Association. Circulation 2013;127:e6-245.

4. Chau PH, Woo J, Chan KC, et al. Avoidable mortality pattern in a Chinese population-Hong Kong, China. Eur J Public Health 2011;21:215-20.

5. Truelsen $\mathrm{T}$, Mahonen $\mathrm{M}$, Tolonen $\mathrm{H}$, et al. Trends in stroke and coronary heart disease in the WHO MONICA Project. Stroke 2003:34:1346-52.

6. Wu Z, Yao C, Zhao D, et al. Sino-MONICA project: a collaborative study on trends and determinants in cardiovascular diseases in China, part i: morbidity and mortality monitoring. Circulation 2001;103:462-8.

7. Schmidt M, Jacobsen JB, Lash TL, et al. 25 year trends in first time hospitalisation for acute myocardial infarction, subsequent short and long term mortality, and the prognostic impact of sex and comorbidity: a Danish nationwide cohort study. BMJ 2012;344:e356.

8. Smolina K, Wright FL, Rayner M, et al. Determinants of the decline in mortality from acute myocardial infarction in England between 2002 and 2010: linked national database study. BMJ 2012;344: d8059.

9. O'Flaherty M, Ford E, Allender S, et al. Coronary heart disease trends in England and Wales from 1984 to 2004: concealed levelling of mortality rates among young adults. Heart 2008;94:178-81.

10. Ford ES, Capewell S. Coronary heart disease mortality among young adults in the U.S. from 1980 through 2002: concealed leveling of mortality rates. J Am Coll Cardiol 2007;50:2128-32.

11. McGhee SM, So JC, Thomas GN. Explaining coronary heart disease trends in Hong Kong: creation of a model for policy and planning. Hong Kong Med J 2009;15(Suppl 2):22-5.

12. Meade TW, Imeson J, Stirling Y. Effects of changes in smoking and other characteristics on clotting factors and the risk of ischaemic heart disease. Lancet 1987;2:986-8.

13. Bakhru A, Erlinger TP. Smoking cessation and cardiovascular disease risk factors: results from the Third National Health and Nutrition Examination Survey. PLoS Med 2005;2:e160.

14. Janus ED, Cockram CS, Fielding R, et al. Hong Kong Cardiovascular Risk Factor Prevalence Study 1995-1996. Hong Kong: Department of Clinical Biochemistry, Queen Mary Hospital of Hong Kong. 1997.

15. Department of Health. Report on Population Health Survey 2003/ 2004. Hong Kong: Department of Health of Hong Kong Special Administrative Region and Department of Community Medicine of the University of Hong Kong, 2005. http://www.chp.gov.hk/files/
pdf/Heart Health Survey en 20071109.pdf (accessed 11 Jan 2013).

16. Department of Health. Heart Health Survey 2004/2005. Hong Kong: Department of Health, 2007. http://www.chp.gov.hk/files/ pdf/Heart_Health_Survey_en_20071109.pdf (accessed 11 Jan 2013)

17. He FJ, MacGregor GA. Reducing population salt intake worldwide: from evidence to implementation. Prog Cardiovasc Dis 2010;52:363-82.

18. Basu R, Samet JM. Relation between elevated ambient temperature and mortality: a review of the epidemiologic evidence. Epidemiol Rev 2002;24:190-202.

19. Barnard LF, Baker MG, Hales S, et al. Excess winter morbidity and mortality: do housing and socio-economic status have an effect? Rev Environ Health 2008;23:203-21.

20. Yan YY. The influence of weather on human mortality in Hong Kong Soc Sci Med 2000:50:419-27.

21. Chau $\mathrm{PH}, \mathrm{Chan} \mathrm{KC}$, Woo J. Hot weather warning might help to reduce elderly mortality in Hong Kong. Int J Biometeorol 2009:53:461-8.

22. Thach TQ, Wong CM, Chan KP, et al. Daily visibility and mortality: assessment of health benefits from improved visibility in Hong Kong. Environ Res 2010;110:617-23.

23. Steptoe A, Kivimaki M. Stress and cardiovascular disease. Nat Rev Cardiol 2012:9:360-70.

24. Leung LC, Chan KW. Understanding the masculinity crisis: implications for men's services in Hong Kong. Br J Soc Work 2012 doi:10.1093/bjsw/bcs122

25. Chau PH, Yen E, Morley JE, et al. The effects of environmental stressors on the mortality of the oldest old male population in Hong Kong, 1977-2006. Aging Male 2008;11:179-88.

26. Wong SL, Donnan SP. Influence of socioeconomic status on cardiovascular diseases in Hong Kong. J Epidemiol Community Health 1992;46:148-50.

27. Schooling CM, Lam TH, Thomas GN, et al. Growth environment and sex differences in lipids, body shape and diabetes risk. PLoS ONE 2007; $2:$ e1070.

28. Law CM, Shiell AW, Newsome CA, et al. Fetal, infant, and childhood growth and adult blood pressure: a longitudinal study from birth to 22 years of age. Circulation 2002;105:1088-92.

29. Cheung YF, Wong KY, Lam BC, et al. Relation of arterial stiffness with gestational age and birth weight. Arch Dis Child 2004;89:217-21.

30. Yi Z, Gu D, Land KC. The association of childhood socioeconomic conditions with healthy longevity at the oldest-old ages in China. Demography 2007;44:497-518.

31. Chau PH, Woo J, Gusmano MK, et al. Access to primary care in Hong Kong, Greater London and New York City. Health Econ Policy Law 2013;8:95-109.

32. Vukmir RB. Survival from prehospital cardiac arrest is critically dependent upon response time. Resuscitation 2006;69:229-34.

33. Kudenchuk PJ, Redshaw JD, Stubbs BA, et al. Impact of changes in resuscitation practice on survival and neurological outcome after out-of-hospital cardiac arrest resulting from nonshockable arrhythmias. Circulation 2012;125:1787-94.

34. Leung LP, Lo CM, Tong HK. Prehospital resuscitation of out-of-hospital cardiac arrest in Queen Mary Hospital. Hong Kong J Emerg Med 2000;7:191-6.

35. The University of Hong Kong Cardiopulmonary Resuscitation Knowledge Study Group. Knowledge of cardiopulmonary resuscitation among the public in Hong Kong: telephone questionnaire survey. Hong Kong Med J 2003:323-8.

36. Chung $\mathrm{CH}$, Wong PCY. A six-year prospective study of out-of-hospital cardiac arrest managed by a voluntary ambulance organisation. Hong Kong J Emerg Med 2005;12:140-7.

37. Dickinson HO, Mason JM, Nicolson DJ, et al. Lifestyle interventions to reduce raised blood pressure: a systematic review of randomized controlled trials. J Hypertens 2006;24:215-33.

38. Sacks FM, Svetkey LP, Vollmer WM, et al. Effects on blood pressure of reduced dietary sodium and the Dietary Approaches to Stop Hypertension (DASH) diet. DASH-Sodium Collaborative Research Group. N Engl J Med 2001;344:3-10.

39. Cheung BMY, McGhee SM, Lau CP, et al. Cost-effectiveness of low-salt diet for lowering blood pressure in Hong Kong Chinese population. Hong Kong Med J 2007;13:32-6.

40. Woo J, Leung SS, Ho SC, et al. Dietary intake and practices in the Hong Kong Chinese population. J Epidemiol Community Health 1998;52:631-7.

41. The Chinese University of Hong Kong. Increasing salt intake predisposes Hong Kong people to hypertension and its complications. 2005. http://www.cuhk.edu.hk/cpr/pressrelease/ 050511e.htm (accessed 11 Jan 2013). 
42. World Health Organization. Prevention of cardiovascular disease: guidelines for assessment and management of total cardiovascular risk. Geneva: World Health Organization, 2007.

43. Appel LJ, Espeland MA, Easter L, et al. Effects of reduced sodium intake on hypertension control in older individuals: results from the
Trial of Nonpharmacologic Interventions in the Elderly (TONE). Arch Intern Med 2001;161:685-93.

44. Woo J, Sea MM, Tong P, et al. Effectiveness of a lifestyle modification programme in weight maintenance in obese subjects after cessation of treatment with orlistat. J Eval Clin Pract 2007;13:853-9. 